\title{
Evolution of heart transplantation since Barnard's first
}

\author{
Mariano Francisco del Maria Javier ${ }^{1}$, Eva Maria Javier Delmo ${ }^{2}$, Roland Hetzer ${ }^{1}$ \\ ${ }^{1}$ Cardio Centrum Berlin, Berlin, Germany; ${ }^{2}$ Universitätsmedizin Berlin-Charité, Charité Research Organisation, Berlin, Germany \\ Contributions: (I) Conception and design: All authors; (II) Administrative support: None; (III) Provision of study materials or patients: EM Javier \\ Delmo, R Hetzer; (IV) Collection and assembly of data: All authors; (V) Data analysis and interpretation: All authors; (VI) Manuscript writing: All \\ authors; (VII) Final approval of manuscript: All authors. \\ Correspondence to: Mariano F. D. M. Javier, MD. Cardio Centrum Berlin, Unter den Linden 21, 10117 Berlin, Germany. Email: mfdmjavier@yahoo.de.
}

\begin{abstract}
Barnard's first human heart transplantation in 1967 has paved the channel to numerous extensive researches and clinical experiences, mostly from the Stanford group, on orchestrating criteria for donor and recipient selection, immunosuppression, distant heart procurement, re-transplantation, and further global performance of the procedure until it became the gold standard therapy for end-stage heart failure, even in the face of an utterly limited organ availability. Much has happened since Barnard's first. There has been a rapid rise to 4,000-5,000 transplants per year. Previously, the number of transplants depended on the capacity of the units. Later on, it depended largely on the availability of donor organs. The widening of indications and reduction of contraindications to heart transplantations to include elderly patients $>70$ years, systemic diseases such as amyloidosis, has emerged. Indeed, heart transplantation has come a long way, and is considered a fruitful and stimulating episode in modern medicine. It is rather deplorable to watch that in the beginning of 1990s, the yearly number of heart transplantations began to decline-not because the operation had proved unsuccessful, but because donor hearts became scarce. It is rather poignant that although science and technology as well as increased experience accumulated over a long time have paved the way to make such an operation possible, its applicability is limited by lack of public awareness or its unwillingness to agree to organ donation. The average transplant survival is now over 10 years. Its prevalence and success, however, belies the fact that over 52 years ago, no one had ever attempted the procedure in man and that the procedure seemed destined for ignominy and failure just a year after the first transplant. Had it not been for the work of a few scientists and physicians, each who stepped on the broad shoulders of those who had come previously, the history of heart transplantation would be nothing more than a few legends and myths in dusty tomes.
\end{abstract}

Keywords: Heart failure; heart transplantation; brain death; allograft rejection; immunosuppression; distant heart procurement; re-transplantation

Submitted Feb 15, 2020. Accepted for publication Apr 22, 2020.

doi: $10.21037 / \mathrm{cdt}-20-289$

View this article at: http://dx.doi.org/10.21037/cdt-20-289

\section{The first}

The evolution of heart transplantation neither begun nor ended with Barnard's first (1). Looking back, man imagined the possibility of transplantation for thousands of years. Greek mythology had many descriptions of chimeras, including animals with a head of a lion but the body of a goat (2). These creatures, if not exactly transplant recipients, did possess organs of more than one species and perhaps sparked the imagination of early scientists. Relished with icons and challenges, the evolution of cardiac transplantation marks one of the greatest victories in contemporary medicine.

The most fascinating aspect about heart transplantation may not be its occurrence, but that its advancement underlies the unique collaboration of basic scientific experimentation, surgical technique and medical forethought. 
A little more than 52 years ago, on the $3^{\text {rd }}$ of December, 1967 , the world agaped by the reportage of the first human heart transplantation, performed by Christian Barnard in Cape Town, South Africa, on 54-year-old Louis Washkansky, who suffered from ischemic cardiomyopathy and was admitted for terminal heart failure. The donor heart came from a trauma victim with massive cerebral injuries. While the recipient was being prepared for transplantation, her heart was harvested using the technique developed by Shumway and perfused mechanically at $10{ }^{\circ} \mathrm{C}$. To prevent postoperative rejection, the recipient was given a cocktail of local irradiation, azathioprine, prednisone, and actinomycin C. Despite efforts at maintaining a sterile environment, the patient died of a Pseudomonas pneumonia and a nascent acute rejection on the 18th postoperative day. The second patient, Philip Blaiberg lived for 18 months and this of course was a major stimulus (1).

Barnard mainly had the courage to perform "The Operation", as he titled the publication of this event (1), at a time of scientific turmoil regarding unanswered questions and unknown aspects in the field of transplantation. After Hardy's ill-fated xenotransplant (3) and public attention, he had taken much criticism from the medical community. Nevertheless, Barnard performed a second transplant less than a month later, on January 2, 1968. The patient, Philip Blaiberg, lived for 593 days before dying of graft atherosclerosis (4), although his quality of life was questionable (5). Publicity by this time had become outrageous.

\section{The second and beyond}

Three days (December 6, 1967) after Barnard's first, Kantrowitz from Maimonides Medical Center in Brooklyn, New York performed the second. The donor heart was retrieved from an anencephalic donor and transplanted to a 17-day-old newborn with a severe Ebstein's anomaly. Albeit the formidable challenge proffered by a very young age of the recipient, Kantrowitz performed the heart transplantation using hypothermic circulatory arrest, achieving spontaneous sinus rhythm 10 minutes after the transplantation. Six and half hours later, the baby developed severe respiratory and metabolic acidosis and in spite of exhaustive resuscitation measures, the infant succumbed (6).

Nevertheless, the first era of heart transplantation had arrived. On January 6, 1968, Norman Shumway, the man many had expected to be the first to attempt human heart transplantation, performed procedure for the first time (7). The recipient, 43-year-old Michael Kasperak, lived just 15 days. According to their report (7), the surgeons were faced with a donor heart size inferior to that of the recipient. The transplant surgeons consequently tailored the anastomotic suture lines in order to obtain sufficient circumferences. Preoperative azathioprine and methylprednisolone and postoperative prednisone, azathioprine and methylprednisolone were administered to counteract rejection. However, oliguria dominated the entire postoperative course, during which the patient had to undergo an emergency cholecystostomy and an exploration for severe upper gastrointestinal bleeding, each via an open laparotomy. The latter operation was followed by sepsis from gram-negative bacteria, from which the patient expired on the $15^{\text {th }}$ postoperative day $(7,8)$. Shumway, however, was the tortoise to Barnard's hare. He had not pioneered, but would continue to advance the field of transplantation for the next 20 years. The year 1968, however, found surgical teams in 14 countries-most with less experience or expertise than Shumway-performing the new procedure. More than one hundred transplants were performed in 1968, with only 40 patients alive on $9^{\text {th }}$ postoperative day (9). As Shumway succinctly summed up the problem, "suddenly heart transplantations were being performed in centers where one would scruple to have a closure of his atrial septal defect" (10). The initial enthusiasm soon expired as surgeons and medical centers learned that many problems remained unsolved, the initial enthusiasm soon expired. By 1970, the number of centers still performing heart transplants had diminished to 10 and at least one medical bulletin asked, "What Ever Happened to Heart Transplants?" They had withdrawn from the public sphere and reentered the realm of thoughtful researchers like Shumway. Behind the curtains, Shumway continued to solve the many problems that still confronted transplantation surgeons.

\section{Brain death}

One major and controversial issue was that of brain death. An ad hoc committee rapidly convened at Harvard Medical School in 1968 to address this topic, and their recommendations had seemingly freed doctors from the thorns of this dilemma (11). The Harvard committee enumerated and specified attributes that qualifies irreversible coma to be the 'new criterion of death.' Tests to evoke the presence or absence of reflexes and central 
nervous system activities, spontaneous respiration and movements have been recommended. A repetition of these tests after 24 hours has also been advocated assuming that there has no change in the person's status. The two reasons included in the report on the need to modify the definition of death at this time were: (I) patients could still have a beating heart although with an irreversible brain damage due to refinements in resuscitation and support management (11), which is an event imposing a tremendous load not only on these patients themselves but also to their families as well as to the institutions with regards to bed allocations, and (II) to address the controversial issue of obtaining donor organs for transplantation with regards to the classical criteria for ascertaining death (11). The Harvard report advocated then that a patient could be pronounced dead before discontinuance of mechanical ventilatory support- a decision performed by doctors who were not concerned in transplantation to obviate any conflicts of interest and ethical repercussions (11). This counsel sanctioned harvesting of organs while the heart still beats. However, the predicament came to the forefront one final time in 1973, and again Norman Shumway was involved. Shumway had used a donor organ from a shooting victim. When the murderer came to trial, the accusing lawyer shrewdly asserted that it had been Shumway disconnecting the respirator, rather than his client pulling the trigger, as the reason for death (12).

\section{Recognition of transplant rejection}

Perhaps a more pressing issue was that of transplant rejection: how to diagnose rejection and how to manage it. Several years earlier, Lower and Shumway had first considered using cardiac enzymes as a means of diagnosis, however soon discarded this idea, and by 1964, had settled on electrocardiographic amplitude as a means of monitoring rejection in their canine transplants (13). Stinson in 1969 (14) viewed that clinical and physiological observations suggested myocardial restriction as the primary functional lesion in heart transplant rejections and supported the ECG as the most sensitive and reliable monitor of cardiac rejection.

Clearly, this technique, although noninvasive, was suboptimal. By 1973, Caves and Billingham, part of Shumway's group, had developed the technique of percutaneous endomyocardial biopsy-regarded at that time as the ultimate diagnostic modality. Early work with azathioprine, steroids, and even radiation, although promising, was not definitive (15).

In the same year 1969 (16), the group had used the combination of azathioprine, prednisone, and antilymphocyte globulin as the basic immunosuppressive agents in 11 of 13 patients. Likewise, primary surgical aspects of cardiac transplantation have been reported, including complications of wound healing, cardiac rhythm disturbances and immediate allograft failure in four patients (17). They confirmed that the technical feasibility of cardiac transplantation and the prerequisite social, legal and ethical considerations involved in donor organ procurement from neurologically dead donors presented no impediment to the full application of this procedure (18).

Transplantation of all organs would change when researchers at Sandoz Laboratories isolated the fungus Tolypocladium inflatum in 1970 from Norwegian soil samples and subsequently developed the immunosuppressant cyclosporine A (19) and was used in experimental heart transplantation in 1978 (20).

Although the rejection issues would continue to plague future generations of transplant physicians, Shumway had guaranteed the prospects of success. By 1985, Baldwin and Shumway reported a 1 -year survival rate exceeding $80 \%$, with an expected full rehabilitation of $80 \%$ of the 1-year survivors (21). Heart transplantation had found its way back into the clinical realm - permanently this time.

Within two months of Barnard's first cardiac transplantation, on February 16, 1968, Sen and his team followed suit in India, considered the $6^{\text {th }}$ in the world (22). However, 15 minutes after the patient had been weaned from cardiopulmonary bypass, the right ventricle began to enlarge rapidly and had to be vented, while the left side maintained normal contraction. Despite all measures, the heart stopped functioning 3 hours after the transplantation (23). On $13^{\text {th }}$ September the same year, Sen and his team attempted another transplant. This time, the heart functioned for 14 hours, before the patient died of anuria. Autopsy revealed pulmonary hypertension, multiple pulmonary emboli, and renal tubular damage. Henceforward, no further transplants were attempted in India for 28 years, as India struggled to construct proper laws concerning definition of brain death and organ donation (24).

On April 27, 1968, Cabrol came to prominence when he performed the first cardiac transplant in Europe, at Pitié-Salpêtrière Hospital. Unfortunately, his patient, 66-year-old Clovis Roblain, lived for only 53 hours $(25,26)$. However, he and his group persisted when others hesitated, 
seeing clearly the potential for a greater impact. In the late 1960's and early 1970's, Shumway's team at Stanford and Cabrol's group in Paris were almost alone in keeping heart transplantation alive. Always in the vanguard, Cabrol went on to perform the first heart and lung transplant in Europe in 1982 (27), and then in 1986 performed the first implantation of the Jarvik 7 total artificial heart (28).

It was on May 3, 1968 that the South African-born Ross led his team in London to perform the first heart transplantation in United Kingdom, which was the $10^{\text {th }}$ heart transplant after that of Barnard. The operation (29), on a 45-year-old man named Frederick West, lasted 7 hours. The patient survived for 46 days before dying from "an overwhelming infection", which later was understood as an acute rejection. There had been a surge of media attention around heart transplantation, but the team had not considered the surgery itself particularly unique or challenging. At a time before the development of modern immunosuppressive drugs, the difficulty of preventing rejection was a key problem with all transplant surgery. Ross's breakthrough therefore proved something of a false dawn. Only six more heart transplants were carried out in Britain before a moratorium was declared. English (30) reinitiated it in 1979 in Papworth followed by Yacoub in Leeds in the 1980s (31). Since 2011, well over 100 heart transplants are performed annually in the UK (32).

In another transplant survival investigative studies rendered by Cooley and his team at Baylor University College of Medicine, significantly longer survival times than those of preliminary studies were attained. Commencing in May 1968, the team carried out 10 human heart, 1 heartlung and a xenograft (sheep-to-human) transplantations (33). To anticipate transplantation success, blood-group compatibility, lymphocyte crossmatch studies and a scoring system were used. Furthermore, concomitant to the classical anti-rejection management, an antilymphocyte globulin was added. With this armamentarium, Cooley's group described that 7 human heart transplant patients were alive until 4.5 months post-transplantation $(33,34)$.

These chronicles illuminated the more successful transplantations performed by the celebrated cardiothoracic surgeons of the time. Nonetheless, their promising results were not reflective of the actual transplantation outcome of newly born heart transplant programs, which had rapidly sprouted. The year after Barnard's first, 102 heart transplantations were carried out, albeit successively unsuccessful. Shumway famously uttered that heart transplantation propped up in scrupulous areas wherein a closure of a simple hole in the heart has not even been done (10). Hence, with insufficient knowledge of rejection diagnosis and treatment combined with lack of comprehension about transplant rejection, the inexperienced groups eventually abandoned heart transplantation. All through this desolate time in the history of heart transplantation, Shumway's group persevered.

The year 1969 had brought forth European icons in the history of heart transplantation. Moll from the Medical Academy in Lódź carried out the first heart transplantation in Poland on January 4, 1969 (35). The first heart transplantation in Germany, which unfortunately was unsuccessful, was performed in February 13, 1969 by Zenker, Sebening and Klinner in Munich on a 36-yearold recipient, who survived for 27 hours (36). The high rate of early lethality initially shown by many groups due to rejection caused greater reluctance in Germany around 1969. This did not change until cyclosporine became increasingly available in the 1980s, allowing control of the rejection reaction (37-39). Bücherl initiated the first heart transplantation in Berlin, albeit unsuccessful, also in this same year (40). By 1970, these groups abandoned heart transplantation, having been regarded as not feasible.

Senning and his team performed the first heart transplant in Zurich, Switzerland on April 4, 1969 (41). The recipient was a 54-year-old businessman, declared to be in a "very satisfying state" postoperatively. Senning stated in an interview that transplantation is technically simple, "One must merely sew. And when one knows where to sew, there is no problem" (41).

The experience of the Stanford group with 26 human heart transplantations reported in 1971, demonstrated a survival of $42 \%$ at 6 months, $37 \%$ at 18 months and $26 \%$ at 2 years (42). In 1973, Shumway's group reported the 3 -year outcome in 29 transplants, noting survival rates of $39 \%, 37 \%$ and $30 \%$ at 6 months, 18 months and 2 years, respectively $(8,43)$. Shumway then illustrated and defined unprecedented challenges with increasing experience in long-term heart transplant survivors. Among 13 discharged transplant patients 5 had 12 late acute rejection episodes considered milder compared to the severe early acute rejection occurring right after transplantation (8). Prednisone administration proved to be successful therapy for late acute rejection. However, chronic rejection, exemplified as diffuse allograft vasculopathy, which predisposed to sick sinus syndrome and myocardial infarction have been the risk factors for long-term survival of post-transplant patients (43). 
It became then apparent that early recognition of acute rejection plays a major role in transplant survival. This has been observed to occur within 2 months posttransplantation with significant reduction in incidence and severity thereafter. Rejection has been previously considered with occurrence of electrocardiographic changes (low QRS voltage, rhythm disturbances, right axis deviation, and ST-T wave changes) concomitant with gallop rhythm and hypotension, seen on 60 rejection episodes (44). Antirejection treatment included administration of triple therapy - methylprednisolone, actinomycin D, and antilymphocyte globulin, which were observed successful on 57 rejection episodes (44).

The Stanford group further advanced the heart transplantation to a higher status when they introduced histological confirmation of rejection obtaining small myocardial tissue samples with the application of percutaneous transvenous endomyocardial biopsy in 1973, deemed to pose minimal risk to the patient (14), initially used in laboratory animals. Eventually, this procedure was added to the Stanford post-transplant management scheme, which included serial tissue histological analysis to validate even minor occurrence of rejection immediately after transplantation. The following year [1974], the group observed actuarial survival rates of $43 \%, 40 \%$ and $26 \%$ at 1,2 and 3 years, respectively, in 59 heart transplants $(45,46)$. With increasing experience in heart transplantation and better understanding of phases of rejection, the group demonstrated longer patient survival. It is uncontested that towards the end of 1970s, Shumway attained a splendid transplantation outcome with the limited available technology. At this time, the perpetual search for a perfect immunosuppression continued.

\section{Immunosuppression}

The introduction of lymphocytic rabbit anti-thymocyte globulin (ATG) in 1973 provided a potent, somewhat more targeted immunosuppressive strategy $(47,48)$. The Stanford group (49-52) substituted the use of rabbit ATG for human ATG and discovered an apparent prolongation of time to onset of initial postoperative rejection episodes as well as reduction in the frequency of rejection episodes compared to their previous experiences $(48,53)$.

The almost simultaneous adoption of percutaneous endomyocardial biopsy and rabbit ATG constituted a major improvement in the immunosuppressive strategy.

Cyclosporine sprung up not as fast as a lightning does.
It took around 4 years from an in vitro experiment until its human application. Thanks to Borel who first reported in 1976 the immunosuppressive values of cyclosporine A (54). Cyclosporine A is lymphocyte specific, a fungal metabolite product extracted from Swiss soil, first used in laboratory animals $(55,56)$. At that time, cyclosporin A was used in vivo in porcine cardiac allografts, and illustrated its potency over any other anti-immunosuppression agents in rejection suppression. Ultimately, its non-toxicity a well as its efficacy paved the road to its human application (56).

In 1980, Shumway et al. braved themselves to integrate cyclosporin A as part of their immunosuppression armamentarium, first experimenting on three doses until finding an effective one. By doing so, they reported at the end of that year that the cumulative survival rates increased to $63 \%, 56 \%$, and $52 \%$, at 1-, 2-, and 3-year, Ultimately, heart transplantation gained worldwide acceptance $(57,58)$ leading to an stalwart increase in performance of heart transplantation as a highly rational option in management of end-stage heart failure.

\section{Distant heart procurement}

Distant heart procurement which has greatly alleviated the scarcity or paucity of donor hearts was conceived by the Stanford group and ultimately developed satisfactory organ preservation methods to minimize ischemic time of donor hearts. Watson and team (59) performed the initial experience with distant heart procurement in Stanford in September 1973, when a donor heart was removed at a hospital $70 \mathrm{~km}$ away and transported for implantation. The ischemic time of this heart was 110 minutes and the patient's postoperative course was uncomplicated. Based on this initial experience and an increasing number of waiting recipients, active efforts in distant heart procurement were begun in mid-1977 using a simple preservation technique of an initial perfusion and simple cold storage. Using standard techniques of myocardial preservation, predominantly topical hypothermia, it showed that anoxic arrest can be tolerated with acceptable post-arrest function in the normal heart up to 3 hours. They advocated further attempts be made to minimize the ischemic interval and a strict adherence to sterile technique in the retrieval of distant hearts.

Billingham et al. (60) described the ultrastructural changes of the transported hearts at maximal ischemic time and compared these morphologic changes with those from on-site donor heart. The group reported that donor hearts 
with a maximal ischemic time of 4 hours still had dense core granules in sympathetic nerve endings. Except for endothelial changes, the ultrastructural changes observed appear reversible. Hence, it became apparent that a simple preservation technique can be used to preserve donor hearts for 3-4 hours with satisfactory function and survival of the recipient.

Since then, distant heart procurement has been a major step forward in providing an increased number of donors and in decreasing the time interval from acceptance to transplantation, thereby decreasing the mortality rate of awaiting recipients.

The enactment of laws codifying brain death and the introduction of distant donor procurement in 1973 were incremental contribution to augment the clinical experiences (59).

At Stanford during the following four years, every year 20-30 heart transplantations were performed with highly selected recipients and donors standardized pre-intra-andpostoperative procedure, which during this time became firmly established from the criteria set by Rider et al. (61) in 1975 such as the recipient must be $>15$ but less than 50 years old without elevated pulmonary vascular resistance, with completely reversible PVR, no infection, no recent thromboembolism, no other organ dysfunction, no diabetes or other systemic disease, in stable family or relationship, psychologically stable and compliant, no smoking, no drugs, no alcohol; the donor must be $<35$ years old (for fear of transplanting hearts with early coronary artery disease), no resuscitation, no arrhythmia, no cardiac anomalies, no infection, no diabetes, no signs of atherosclerosis. and with irreversible brain death. Established contraindications included: advanced renal or hepatic dysfunction or significant gastrointestinal disease any systemic infection or pulmonary infarction and severe elevation of pulmonary vascular resistance secondary to long-standing left ventricular failure or pulmonary emboli, as manifested by a calculated pulmonary vascular resistance greater than 8 Wood units (61). By 1978 the results in Stanford were so convincing that other centers readily took up transplant program (62).

Increased survival rates then were borne out of their accumulated experience in multiple aspects of cardiac transplantation, including more stringent donor and recipient selection, routine use of cardiac biopsy for the diagnosis of rejection, and modifications in the treatment of graft rejection.

\section{Re-transplantation}

At some point in Stanford's expanding experience in heart transplantation, the group was confronted with immediate post-transplantation intractable ventricular tachyarrhythmias, early postoperative intractable acute rejection and late development of severe donor coronary arteriosclerosis, all heralding current or impending cardiac allograft failure, in 5 consecutive patients beginning in 1968 (63). To offset these complications, the group opted for cardiac re-transplantation as a rescue procedure. Subsequent refinement of criteria for selection of both recipients and cardiac donors has then eliminated, if not completely solved, such incidents. Nevertheless, although two of these patients died 12-21 days after retransplantation, the successful outcome in two patients reported in this series illustrated the potential value of cardiac re-transplantation for prolongation of survival and rehabilitation in selected cases. The concept has been accepted widely by the transplant community including patients. This has set the stage for the applicability of cardiac re-transplantation but until now is of limited availability. The group (63) then established that cardiac re-transplantation be performed in previously transplanted patients with severe accelerated graft atherosclerosis (allograft failure). The absolute (increased pulmonary vascular resistance, ongoing infection, positive donorspecific lymphocyte crossmatch, insulin-dependent diabetes dysfunction) and the relative (advanced age, psychosocial instability) contraindications to transplantation remained the same for cardiac re-transplantation.

Re-transplantation has clearly demonstrated survival prolongation, albeit the reported cases were low and the procedures were done during the pre-cyclosporine era $(59,63)$ and a survival rate more or less half $(30 \%)$ of the initial transplanted hearts $(60 \%)$ at 1 year (59). Further Stanford studies on re-transplantation using cyclosporine immunosuppression affirmed that although there has been a great improvement in survival rates of primary transplanted patients with decreased morbidity and mortality from infection and an apparent decline in the severity of the rejection episode, re-transplantation for acute allograft rejection still remained as the primary indication for retransplantation, as it was in the pre-cyclosporine era, as a rescue strategy and re-transplantation should only be offered selectively in recipients who met the strict criteria (64). The expected outcome for these patients is not as good as that for patients who undergo primary transplantation, 
however, and this fact should also be considered when scarce donor hearts become available. Wherefore, with regards to the meagerness of organ donor, serious ethical considerations have then become an issue.

In 1968, Cooley performed the first heart and lung transplantation followed by Lillehei in 1969 and Barnard in 1971, all unsuccessful (65). Shumway and Reitz performed the world's first successful combined heart-lung transplantation in 1981 (66), synchronous to the restart of heart transplantation in Munich, Germany by its two centers. Between August 1981 and August 1983, 11 heart transplantations were carried out and Cyclosporin A was used as the main immunosuppressive agent in all cases. Three patients died (1, 10, and 73 postoperative day), whilst 8 patients survived for 2 to 25 months. The survival time exceeds 0.5 years in 5 cases and 1 year in 3 cases (40).

This revival of heart transplantation in Germany was not overlooked. On July 21, 1983, Hetzer, who was a cardiac surgery fellow in Stanford University in the transplantation program, performed the first heart transplantation in Hannover Medical School. The recipient was a 46 year-oldman who was extubated 10 hours after the surgery and lived for 4 months. The legendary performance was immediately picked up by the media, and sparked public acceptance; hence, successive heart transplantations followed. Within a span of 2 years, Hetzer performed 72 heart transplantations, with some patients surviving for $>20$ years and one alive for $>32$ years, he relocated to Berlin and launched an engaging platform in heart transplantation in April 1986, performing by September 2014, 1,804 heart transplantations, 51 retransplantations and 100 heart and lung transplantations, the largest heart transplantation experience in the country $(67,68)$.

\section{Pediatric heart transplantation}

On June 9, 1984, the world's ever first successful pediatric heart transplantation was performed by Eric Rose in Columbia, New York, on James Lovette, a four-yearold boy with a single ventricle (69). The team improvised by titrating doses of cyclosporine to prevent transplant rejection. However, Lovette struggled with his health for decades, surviving a bout of Hodgkin's Lymphoma and eventually a second heart transplant in 1989. Nevertheless, his transplant at age four enabled his survival till early adulthood. He graduated from college and received a master's degree. Sadly, he passed away in his sleep during his first week of medical school in 2006. In addition to saving the life of one young boy, Rose's 1984 surgery was a pivotal milestone for the field of pediatric transplant surgery (70).

On 1 November 1984, Cooley and associates performed an orthotopic heart transplantation in an 8-month-old baby with end-stage heart failure from endocardial fibroelastosis, the first ever successful endeavor in an infant after the failed attempt of Kantrowitz in December 1967. The donor heart came from an unequivocably brain-dead 2-year-old child. On the $7^{\text {th }}$ post-transplantation day, the infant had a severe allograft rejection episode and a moderate rejection phase on the $22^{\text {nd }}$ post-transplantation day, in spite of a regimen of steroids and cyclosporin A. Nevertheless, she was discharged home on the $28^{\text {th }}$ post-transplantation day. She apparently had an impressively good life until November 1997 when she succumbed to a transplant coronary artery disease (70). In 1984, Yacoub performed a heart transplant in a 10-day old baby, and this child survived 18 days (71).

Likewise, in 1984, Bailey from Loma, Linda California, transplanted a 12-day-old girl a donor heart from a baboon, which was famously then named Baby Fae. She survived for 20 days and evolved to be the most famous xenograft transplant recipient (70).

The first pediatric heart transplantation in Germany was successfully executed by Hetzer and his team on March 30, 1985 (68,72). The recipient was a 9-year-old boy with familial dilative cardiomyopathy who was transplanted with an adult heart. He lived for 16 years with the transplanted heart (mean survival time after heart transplantation that time was $10-12$ years). Unfortunately, like many others who had been transplanted, he developed renal failure from the toxic effect of immunosuppression. He received a kidney transplant from his mother but died suddenly after the transplantation (73). Hetzer recalled that "it was a natural thing to accept the challenge of a pediatric transplantation," adding that the real challenge was transplanting infants, something he later undertook in Berlin.

The largest pediatric heart transplantation series was reported by Bailey and his group. They have performed 421 pediatric heart transplantations over a 24 -year period [1985-2009], with a median follow-up of 9.7 years and a mortality rate of $40.1 \%$ (74). The first successful neonatal heart transplantation for hypoplastic left heart syndrome was performed by Bailey in 1985 (75).

The decades of the 1980s and 1990s have witnessed a continuous refinement of techniques to adjustment of immunosuppressant dosages not only to safeguard the transplanted heart but also to strengthen the immune system to resist infection. In 1994, A new drug, tacrolimus 
(FK-506), originally discovered in a fungus sample, was approved in 1984 as an immunosuppressant for transplanted patients. At that time, innovative modifications in cyclosporine doses (low with minimal toxicity) have been introduced to enhance its efficacy.

Advances in immunosuppression have focused mostly on polyclonal and monoclonal antibodies to outweigh steroid-resistant rejection. Until today, there is a continuing research in management, reversal and obviation of chronic allograft vasculopathy, either caused or exacerbated by the indispensable immunosuppression (76). It has been acknowledged that powerful yet specific immunosuppressants and therapy for chronic allograft vasculopathy play a key role to ensure an excellent outcome of heart transplantation.

Hetzer developed a pediatric immunosuppression protocol consisting of a preoperative induction therapy with cyclosporine and/or mycophenolate mofetil followed by intravenous anti-thymocyte globulin at 6 hours posttransplantation on the first 3 days on the first 3 days with prednisolone administered intravenously to decrease the incidence of early rejection. Thereafter, steroids are tapered. This triple therapy (cyclosporine/mycophenolate mofetil/steroids) is given alternately with everolimus in lieu of mycophenolate mofetil, if no contraindications to everolimus exist (76).

Hetzer likewise employed non-invasive remote rejection monitoring, the intramyocardial electrogram (IMEG) and "echocardiograph" developed by his group in 1986 which eventually became the main diagnostic device in their institution. It consists of a telemetric pacemaker implanted during the heart transplantation procedure which permits a highly authentic remote electrocardiogram monitoring and documents electrocardiographic alterations accordant to humoral and cellular rejection. Later, the use of echocardiographic strain and strain rate imaging has become invaluable for a more reliable and comprehensive evaluation of the function of the myocardium with a high sensitivity in myocardial viability, detection of acute transplant rejection and early onset of transplant coronary artery disease. Immunohistology of right ventricular tissue samples are done to track down infiltration of leukocytes, demarcation of endocardium, damage of myocytes and delineation of small vessels. Endomyocardial biopsy is infrequently used in pediatric transplant patients $(77,78)$.

Much has happened since then. There has been a rapid rise to 4,000-5,000 transplants per year. A registry was deemed necessary; hence, in 1981, the International
Society of Heart Transplantation was born-a non-profit, multidisciplinary, professional organization dedicated to improving the care of patients with advanced heart or lung disease through transplantation, mechanical support and innovative therapies via research, education and advocacy. Previously, the number of transplants depended on the capacity of the units. Later on, it depended largely on the availability of donor organs. Up to now more than 130,000 heart transplants are listed in the registry. The widening of indications and reduction of contraindications to heart transplantations to include elderly patients $>70$ years, systemic diseases such as amyloidosis, has emerged (79).

Presently, the longest survivors were close to 38 years (personal communication). The "Berlin Experience" revealed 10 patients living $>31-34$ years after heart transplantation. Moreover, the group of Hetzer studied the growth of transplanted hearts in children over time, and reported highly satisfactory results (80-82).

\section{Frontiers}

New developments are seen on the horizon. Cardiac allograft vasculopathy is a sequel of a chronic inflammatory phase secondary to an initial allograft endothelial injury. Inflammation of the endothelial cells primarily arose as a preservation injury, allograft immune response and possibly chronic cytomegalovirus infection and could be associated with the concomitant risk factors for atherosclerosis. To effectively treat cardiac allograft vasculopathy, a universal strategy is crucial to decrease inflammation in the donor coronary artery tree (83). This entails development of newer immunosuppressants which could modify the response of the immune system in the heart transplant recipient. An intimal thickening on the first year, as detected by an intravascular ultrasound, is used mostly by most multicenter and randomized trials to prognosticate the evolvement, progression and long-term outcome of cardiac allograft vasculopathy. The present-day antiproliferative agents, e.g., sirolimus, everolimus and mycophenolate mofetil, have been shown to decrease first-year allograft rejection and intimal thickening. Longer follow-up is therefore essential to establish their effectiveness in abating cardiac allograft vasculopathy.

Indeed, heart transplantation has come a long way, and is considered a fruitful and stimulating episode in modern medicine. It is rather deplorable to watch that in the beginning of 1990 s, the yearly number of heart transplantations began to decline-not because the 
operation had proved unsuccessful, but because donor hearts became scarce. It is rather poignant that although science and technology as well as increased experience accumulated over a long time have paved the way to make such an operation possible, its applicability is limited by lack of public awareness or its unwillingness to agree to organ donation. Heart transplantation has reduced in numbers in Europe, is stable in North America and slowly growing in the rest of the world.

Be it as it may, it is those who have died while waiting for donor hearts who have provoked the evolution of mechanical and biological attempts to assist the heart when it fails, such as cardiomyoplasty, skeletal muscle ventricles, left ventricular assist devices and many others. Perhaps someday, the development of an efficient, total artificial heart that could be implanted permanently will annihilate the need for cardiac transplantation. To achieve this goal, we must always remember the momentous lesson bestowed on us by the legends of cardiac surgery: nothing can replace a well-supported and clearly planned research effort to solve the most difficult medical problems.

The average transplant survival is now over 10 years. Its prevalence and success, however, belies the fact that over 52 years ago, no one had ever attempted the procedure in man and that the procedure seemed destined for ignominy and failure just a year after the first transplant. Had it not been for the work of a few scientists and physicians, each who stepped on the broad shoulders of those who had come previously, the history of heart transplantation would be nothing more than a few legends and myths in dusty tomes.

\section{Acknowledgments}

Funding: None.

\section{Footnote}

Provenance and Peer Review: This article was commissioned by the editorial office, Cardiovascular Diagnosis and Therapy for the series "Heart Failure in the Young and Old: Insights into Various Therapies". The article has undergone external peer review.

Conflicts of Interest: All authors have completed the ICMJE uniform disclosure forms (available at http://dx.doi. org/10.21037/cdt-20-289). The series "Heart Failure in the Young and Old: Insights into Various Therapies" was commissioned by the editorial office without any funding or sponsorship. RH served as the unpaid Guest Editor of the series and serves as an unpaid editorial board member of Cardiovascular Diagnosis and Therapy from July 2019 to Jun 2021. The authors have no other conflicts of interest to declare.

Ethical Statement: The authors are accountable for all aspects of the work in ensuring that questions related to the accuracy or integrity of any part of the work are appropriately investigated and resolved.

Open Access Statement: This is an Open Access article distributed in accordance with the Creative Commons Attribution-NonCommercial-NoDerivs 4.0 International License (CC BY-NC-ND 4.0), which permits the noncommercial replication and distribution of the article with the strict proviso that no changes or edits are made and the original work is properly cited (including links to both the formal publication through the relevant DOI and the license). See: https://creativecommons.org/licenses/by-nc-nd/4.0/.

\section{References}

1. Barnard CN. The operation. A human cardiac transplant: an interim report of a successful operation performed at Groote Schuur Hospital, Cape Town. S Afr Med J 1967;41:1271-4.

2. Bazopoulou-Kyrkanidou E. Chimeric creatures in Greek mythology and reflections in science. Am J Med Genet 2001;100:66-80.

3. Hardy JD, Kurrus FD, Chavez CM, et al. Heart transplantation in man. developmental studies and report of a case. JAMA 1964;188:1132-40.

4. Thomson JG. Production of severe atheroma in a transplanted human heart. Lancet 1969;2:1088-92.

5. Blaiberg P. Looking at my heart. Heinemann; London, 1969.

6. Kantrowitz A, Haller JD, Joos H, et al. Transplantation of the heart in an infant and an adult. Am J Cardiol 1968;22:782-90.

7. Stinson EB, Dong E Jr, Schroeder JS, et al. Initial clinical experience with heart transplantation. Am J Cardiol 1968;22:791-803.

8. DiBardino DJ. The history and development of cardiac transplantation. Tex Heart Inst J 1999;26:198-205.

9. Elzinga K. Major medical milestones leading up to the first human heart transplantation. In: Proceedings of the 18th Annual History of Medicine Days Conference 2009: 
The University of Calgary Faculty of Medicine, Alberta, Canada: Cambridge Scholars Publishing, 2011.

10. Patterson C, Patterson KB. The history of heart transplantation. Am J Med Sci 1997;314:190-7.

11. Report of the Ad Hoc Committee of the Harvard Medical School to Examine the Definition of Brain Death. A definition of irreversible coma. JAMA 1968;205:337-40.

12. How to Define Death Is the Issue in Murder Trial. New York Times, May 20, 1974:23.

13. Lower RR, Dong E Jr, Glazener FS. Electrocardiograms of dogs with heart homografts. Circulation 1966;33:455-60.

14. Stinson EB, Dong E Jr, Bieber CP, et al. Cardiac transplantation in man. I. Early rejection. JAMA 1969;207:2233-47.

15. Caves PK, Stinson EB, Billingham M, et al. Percutaneous transvenous endomyocardial biopsy in human heart recipients. Experience with a new technique. Ann Thorac Surg 1973;16:325-36.

16. Stinson EB, Dong E Jr, Bieber CP, et al. Cardiac transplantation in man. II. Immunosuppressive therapy. J Thorac Cardiovasc Surg 1969;58:326-37.

17. Stinson EB, Dong E Jr, Iben AB, et al. Cardiac transplantation in man. 3. Surgical aspects. Am J Surg 1969;118:182-7.

18. Stinson EB, Dong E Jr, Schroeder JS, et al. Cardiac transplantation in man. IV. Early results. Ann Surg 1969; 170:588-92.

19. Borel JF, Kis ZL, Beveridge T. The History of the Discovery and Development of Cyclosporine (Sandimmune®). In: Merluzzi VJ, Adams J. editors. The Search for Anti-Inflammatory Drugs. Birkhäuser Boston, 1995.

20. Jamieson SW, Burton NA, Bieber CP, et al. Survival of cardiac allografts in rats treated with cyclosporin A. Surg Forum 1979;30:289-91.

21. Baldwin JC, Shumway NE. Cardiac transplantation. Z Kardiol 1985;74 Suppl 6:39-43.

22. Mittal CM. Profulla Kumar Sen: His contributions to cardiovascular surgery. Tex Heart Inst J 2002;29:17-25.

23. Sen PK: Human heart homotransplantation. Am J Cardiol 1968;22:826-32.

24. Sen PK: Heart transplantation-The triumph and the muddle. Indian J Chest Dis 1970;12:68-72.

25. Cabrol C, Guiraudon G, Fabre JC, et al. Human heart transplantation. Mem Acad Chir (Paris) 1968;94:506-13.

26. Cabrol C, Gandjbakhch I, Guiraudon G, et al. Heart transplantation. Our experience at the Pitié Hospital in
Paris. Bull Acad Natl Med 1982;166:235-50.

27. Cabrol C, Gandjbakhch I, Pavie A, et al. Heart transplantation. Current status at La Pitié Hospital. Presse Med 1983;12:2521-6.

28. Pavie A, Leger P, Regan M, et al. Clinical experience with a total artificial heart as a bridge for transplantation: the pitie experience. J Card Surg 1995;10:552-8.

29. Ross D. Report of a heart transplant operation. Am J Cardiol 1968;22:838-9.

30. English TA. Heart transplantation---1979. Trans Hunter Soc 1978-1980;37-38:143-51.

31. English TAH, Cooper DKC, Medd R, et al. Orthotopic heart transplantation after 16 hours of ischaemia. Proceedings of European Society for Artificial Organs 1979;6:340-4.

32. Annual Report on Cardiothoracic Organ Transplantation. Report for 2017/2018 (1 April 2008-31 March 2018). Published September 2018. NHS England.

33. Cooley DA, Hallman GL. Results of cardiac transplantation. Laval Med 1970;41:130-3.

34. Cooley DA, Messmer BJ, Hallman GL, et al. Technique and results of human heart transplantation. Stud Gen (Berl) 1970;23:360-78.

35. Lysiak M. Professor Jan Witold Moll (1912-1990): a creator of Poznań thoracosurgery, a pioneer of cardiosurgery in Poland, on the 10th anniversary of his death. Arch Hist Filoz Med 2000;63:47-51.

36. Zenker R, Klinner W, Sebening F. Heart transplantation. Langenbecks Arch Chir 1969;326:1-4.

37. Timmermann W, Calne RY, White DJ, et al. Action of cyclosporin A and cytimun on the survival time of accessory heart transplants. Chir Forum Exp Klin Forsch 1980:139-43.

38. Maugh TA 2nd. New techniques for selective immune suppression increase transplant odds. Science 1980;210:44-6.

39. Reitz BA, Bieber CP, Raney AA, et al. Orthotopic heart and combined heart and lung transplantation with cyclosporin-A immune suppression. Transplant Proc 1981;13:393-6.

40. Schmid C, Schmitto JD, Scheld HH.

Herztransplantationen in Deutschland: Ein geschichtlicher Überblick. Springer-Verlag Berlin Heidelberg, 2003.

41. Cooley DA. In Memoriam: Tribute to Åke Senning, Pioneering Cardiovascular Surgeon. Tex Heart Inst J 2000;27:234-5.

42. Griepp RB, Stinson EB, Dong E, et al. Acute rejection of the allografted human heart: diagnosis and treatment. Ann 
Thorac Surg Aug 1971;12:113-26.

43. Barsness GW, Holmes DR Jr. Coronary Artery Disease: New Approaches without Traditional Revascularization. Springer-Verlag London Limited, 2012.

44. Graham AF, Rider AK, Caves PK, et al. Acute rejection in the long-term cardiac transplant survivor: clinical diagnosis, treatment and significance. Circulation. 1974;49:361-6.

45. Clark DA, Stinson EB, Griepp RB, et al. Cardiac transplantation in man. VI. Prognosis of patients selected for cardiac transplantation. Ann Intern Med 1971;75:15-21.

46. Scheuer J, Shaver JA, Harris BC, et al.

Electrocardiographic findings in cardiac transplantation. Circulation 1969;40:289-96.

47. Bieber CP, Oyer PE, David L, et al. Serum antithymocyte globulin (ATG) and anti-ATG levels in cardiac recipients. Surg Forum 1974;25:285-7.

48. Griepp RB, Stinson EB, Dong E Jr, et al. Use of antithymocyte globulin in human heart transplantation. Circulation 1972;45:I147-53.

49. Bieber CP, Jamieson SW, Raney A, et al. Cardiac allograft survival in rhesus primates treated with total lymphoid irradiation and rabbit antithymocyte globulin. Surg Forum 1979;30:284-6.

50. Bieber CP, Griepp RB, Oyer PE, et al. Use of rabbit antithymocyte globulin in cardiac transplantation. Relationship of serum clearance rates to clinical outcome. Transplantation 1976;22:478-88.

51. Bieber CP, Lydick E, Griepp RB, et al. Radioimmune assay of heterologous serum gamma-globulin in patients receiving rabbit antihuman thymocyte globulin. Transplantation 1975;20:393-8.

52. Bieber CP, Howard FD, Pennock J, et al. Preparation, characterization, and primate testing of monoclonal antithymocyte globulin. Transplantation 1981;31:283-9.

53. Bieber CP, Griepp RB, Oyer PE, et al. Relationship of rabbit ATG serum clearance rate to circulating T-cell level, rejection onset, and survival in cardiac transplantation. Transplant Proc 1977;9:1031-6.

54. Borel JF, Feurer C, Gubler HU, et al. Biological effects of cyclosporin A: a new antilymphocytic agent. Agents Actions 1976;6:468-75.

55. Green CJ, Allison AC. Extensive prolongation of rabbit kidney allograft survival after short-term cyclosporin-A treatment. Lancet 1978;1:1182-3.

56. Calne RY, White DJ, Rolles K, et al. Prolonged survival of pig orthotopic heart grafts treated with cyclosporin A. Lancet 1978;1:1183-5.
57. Shumway NE, Stinson EB, Oyer PE, et al. Heart and heart-lung transplantation. Schweiz Med Wochenschr 1985;115:1571-4.

58. Starnes VA, Shumway NE. Heart transplantation-Stanford experience. Clin Transpl 1987:7-11.

59. Watson DC, Reitz BA, Baumgartner WA, et al. Distant heart procurement for transplantation. Surgery 1979;86:56-9.

60. Billingham ME, Baumgartner WA, Watson DC, et al. Distant heart procurement for human transplantation. Ultrastructural studies. Circulation 1980;62:I11-9.

61. Rider AK, Copeland JG, Hunt SA, et al. The Status of Cardiac Transplantation, 1975. Circulation 1975;52:531-9.

62. Jamieson SW, Stinson EB, Shumway NE. Cardiac transplantation in 150 patients at Stanford University. $\mathrm{Br}$ Med J 1979;1:93-5.

63. Copeland JG, Griepp RB, Bieber CP, et al. Successful retransplantation of the human heart. J Thorac Cardiovasc Surg 1977;73:242-7.

64. Dein JR, Oyer PE, Stinson EB, et al. Cardiac retransplantation in the cyclosporine era. Ann Thorac Surg 1989;48:350-5.

65. Available online: https://www.nytimes.com/1971/07/26/ archives/heartlung-transplant-is-performed-by-barnard. html

66. Reitz BA. The first successful combined heart-lung transplantation. J Thorac Cardiovasc Surg 2011;141:867-9.

67. Hetzer R, Warnecke H, Schüler S, et al. Heart transplantation--a two-year experience. Z Kardiol 1985;74 Suppl 6:51-8.

68. Hetzer R, Hiemann N, Knosalla C, et al. Stand der Herztransplantation 2012. Herzmedizin 4/2012. Mediengruppe Oberfranken.

69. Addonizio LJ, Rose EA. Cardiac transplantation in children and adolescents. J Pediatr 1987;111:1034-8.

70. Bailey LL. The evolution of infant heart transplantation. J Heart Lung Transplant 2009;28:1241-5.

71. Chinnock RE, Bailey LL. Heart Transplantation for Congenital Heart Disease in the First Year of Life. Curr Cardiol Rev 2011;7:72-84.

72. Schüler S, Warnecke H, Fleck E, et al. Hertztransplantation im Kindesalter. Z Kardiol 1989;78:220-7.

73. Hetzer R, Weng Y, Delmo Walter EM. State of the art in paediatric heart transplantation: the Berlin experience. Eur J Cardiothorac Surg 2013;43:258-67.

74. Zuppan CW, Wells LM, Kerstetter JC, et al. Cause of death in pediatric and infant heart transplant recipients: 
review of a 20-year, single-institution cohort. J Heart Lung Transplant 2009;28:579-84.

75. Bailey L, Concepcion W, Shattuck H, et al. Method of heart transplantation for treatment of hypoplastic left heart syndrome. J Thorac Cardiovasc Surg 1986;92:1-5.

76. Erdogan I, Varan B, Sezgin A, et al. Rituximab therapy for rejection in pediatric heart transplant. Exp Clin Transplant 2018;16:199-203.

77. Hetzer R. Potapov E, Müller J, et al. Daily non-invasive rejection monitoring improves long-term survival in pediatric heart transplantation. Ann Thorac Surg 1998;66:1343-9.

78. Warnecke H, Schüler S, Goetze HJ, et al. Noninvasive monitoring of cardiac allograft rejection by intramyocardial electrogram recordings. Circulation 1986;74:III72-6.

79. Khush KK, Cherikh WS, Chambers DC, et al. The International Thoracic Organ Transplant Registry of the International Society for Heart and Lung Transplantation:

Cite this article as: Javier MFDM, Javier Delmo EM, Hetzer R. Evolution of heart transplantation since Barnard's first. Cardiovasc Diagn Ther 2021;11(1):171-182. doi: 10.21037/cdt20-289
Thirty-sixth adult heart transplantation report - 2019; focus theme: Donor and recipient size match. J Heart Lung Transplant 2019;38:1056-66.

80. Hetzer R, Delmo Walter EM. Trends and outcomes in heart transplantation: the Berlin experience. HSR Proc Intensive Care Cardiovasc Anesth 2013;5:76-80.

81. Delmo Walter EM, Huebler M, Stamm C, et al. Adaptive growth and remodeling of transplanted hearts in children. Eur J Cardiothorac Surg 2011;40:1374-82; discussion 1382-3.

82. Delmo Walter EM, Huebler M, Schubert S, et al. Influence of size disparity of transplanted hearts on cardiac growth in infants and children. J Thorac Cardiovasc Surg 2012;143;168-77.

83. Iwanaga K, Hasegawa T, Hultquist DE, et al. Riboflavinmediated reduction of oxidant injury, rejection, and vasculopathy after cardiac allotransplantation. Transplantation 2007;83:747-53. 